\title{
Endopolygalacturonase and the Melting Flesh $(M)$ Locus in Peach
}

\author{
Diane R. Lester ${ }^{1}$ \\ CSIRO Division of Horticulture, GPO Box 350, Adelaide, 5001, Australia \\ Wayne B. Sherman \\ Horticultural Sciences Department, University of Florida, Gainesville, FL, 32611-0690 \\ Brian J. Atwell \\ School of Biological Sciences, Macquarie University, North Ryde, NSW, 2109, Australia
}

Additional index words. RFLP, Prunus persica, fruit ripening

\begin{abstract}
Southern analysis of two ripening-related polygalacturonase (PG) genes of peach [Prunus persica (L.) Batsch] detected a restriction fragment length polymorphism (RFLP) in one that had been previously identified as encoding the endoPG enzyme of melting flesh fruit. This RFLP distinguished the melting flesh cultivars Flavorcrest and Flordaking from the nonmelting flesh cultivars Carolyn, Early Gold Queen, Fla. 86-28C, and Fla. 9-26C. Complete deletion of endoPG-related genomic sequences was demonstrated in the nonmelting flesh variety Fla. 9-20C. In a blind trial, segregation of the endoPG RFLP was followed in relation to the melting flesh trait in a population of 20 trees from 'Fla. 86-28C' $x$ 'Springcrest' in which the trait was segregating 1:1. Cosegregation of the RFLP with the trait occurred for 17 out of 20 trees. Practical aspects of scoring the melting flesh trait in a genetically variable population may account for incomplete segregation. EndoPG protein was detected by western blotting in fruit of the melting flesh cultivars Flavorcrest and Fragar, but not in fruit of the nonmelting flesh cultivar Carolyn. Results from this study and earlier work are used to discuss the hypothesis that the endoPG gene corresponds to the melting flesh $(M)$ locus of peach.
\end{abstract}

The accumulation of knowledge on genetic information of fruit tree species has lagged behind that for most other species of agronomic importance primarily because the generation time of fruit trees is relatively long. Peach is, by far, the best genetically characterized fruit tree species because it has a short generation time, it is diploid $(2 \mathrm{n}=16)$, and it readily self-pollinates (Hesse, 1975). Nearly 30 characters of peach show Mendelian inheritance, and a similar number demonstrates quantitative inheritance (Monet, 1989). For molecular studies, peach has the additional advantage of having one of the smallest genomes of all plants $(265 \mathrm{Mbp} / 1 \mathrm{c}$; Arumuganathan and Earle, 1991). Molecular characterization of the genetics of peach has recently commenced with the publication of two separate genomic maps, one containing 83 randomly amplified polymorphic DNA (RAPD) markers, one isozyme, and four morphological markers (Chaparro et al., 1994) and the other 26 restriction fragment length polymorphism (RFLP) markers (Belthoff et al., 1993).

The melting flesh $(M)$ locus of peach controls firmness of ripe fruit (Bailey and French, 1949). Melting flesh (MF) fruit lose flesh firmness gradually during early ripening, then soften rapidly and dramatically during the final stage of ripening. Nonmelting flesh (NMF) fruit lack the final melting phase of softening and, when fully ripe, remain relatively firm. It is generally accepted that $\mathrm{MF}$ is completely dominant over NMF, but it is also recognized that considerable variation in firmness and texture occurs within the

Received for publication 18 Apr. 1995. Accepted for publication 31 Aug. 1995. This work was supported in part by Pacific Seeds Pty Ltd and the Milthorpe Memorial Fund, Macquarie Univ. We thank Colin Brady and Chris Davies, CSIRO Division of Horticulture, for support and advice; Bruce Topp, Queensland Dept. of Primary Industry, for leaf and fruit samples; and Zeneca Seeds for advice and facilities for the RFLP work. Use of trade names does not imply endorsement of the products named nor criticism of similar ones not named. The cost of publishing this paper was defrayed in part by the payment of page charges. Under postal regulations, this paper therefore must be hereby marked advertisement solely to indicate this fact.

${ }^{1}$ Current address: Dept. of Plant Science, Univ. of Tasmania, GPO Box 252C, Hobart, TAS, 7005, Australia. two phenotypes (Bailey and French, 1949; Monet, 1989; W.B. Sherman, unpublished).

Textural changes of fruit during ripening are the subject of intense study because of their relevance to methods of commercial fruit production, harvest, storage, and sale. The role of the cell wall hydrolase, polygalacturonase (PG), in fruit softening has been studied extensively in tomato by methods that include genetic manipulation. Results from fruit of transgenic plants in which PG activity was reduced by $>99 \%$ using antisense RNA methods were inconclusive and did not support a direct relationship between polygalacturonase activity and tomato fruit softening, as had been suggested by earlier correlative evidence from wild-type plants (Fischer and Bennett, 1991). A mutant tomato with fruit firmness specifically affected has not been reported (Giovannoni et al., 1990).

An endopolygalacturonase (endoPG, EC 3.2.1.15) and an exopolygalacturonase (exoPG, 3.2.1.67) are present in ripe MF peaches (Pressey and Avants, 1973). Collective biochemical evidence implies that the MF trait of peach depends on endoPG activity. Levels of endoPG were greatly reduced in NMF peaches compared to MF fruit, while levels of exoPG activity were similar for the two fruit types (Pressey and Avants, 1978). Throughout ripening, increased endoPG activity was correlated with the advance of softening in a MF cultivar (Orr and Brady, 1993). Changes to pectins attributable to endoPG activity were evident at the latter stage of ripening in MF peaches; these changes did not occur to pectins of NMF peaches (Fishman et al., 1993). Solubilization of pectin was reduced in NMF compared to MF peaches (Fishman et al., 1993; Postlmayr et al., 1956; Shewfelt, 1965). The hypothesis that the endoPG gene corresponds to the $M$ locus is inescapable.

Three distinct PG-related genes showing conservation of $37 \%$ at the derived amino acid level in overlapping regions have been described from peach (Lee et al., 1990; Lester et al., 1994). Two of these genes, represented by cDNAs PRF1 and PRF3, are expressed in ripening fruit (Lester et al., 1994). The prevalent endoPG 
enzyme of MF fruit flesh is encoded by the PRF3-related gene (Lester et al., 1994). A PG enzyme corresponding to the cDNA, PRF1, has not been identified. Northern analysis detected a PRF3related RNA transcript in NMF fruit that was shorter than that of MF fruit (Lester et al., 1994). This provided preliminary genetic evidence that the structure of the endoPG gene differed between MF and NMF cultivars.

In this study, various unrelated MF and NMF cultivars were examined by Southern analysis using the peach PG cDNAs, PRF1 and PRF3. The generation time of peach precluded raising a population specifically for the purpose of mapping endoPG to the melting flesh locus. However, a population of 20 trees in which the melting flesh trait was expected to segregate $1: 1$, which was part of an established breeding program, was studied by RFLP analysis with the endoPG cDNA, PRF3. These trees were subsequently scored blindly as either MF or NMF, and phenotype results were compared with the RFLP analysis. Further, the relationship between endoPG and the MF trait was examined by assaying levels of endoPG protein in cell wall extracts of MF and NMF fruit by immunoblotting.

\section{Materials and Methods}

Plant material. Leaves were collected from the peach MF cultivars Flavorcrest and Flordaking and the NMF cultivars Carolyn, Early Gold Queen, Fla. 9-26C, Fla. 9-20C, and Fla. 86-28C from either Stanthorpe, Queensland, or Gainesville, Fla. Leaves were collected at Gainesville from 20 young trees that were offspring of a cross between the NMF Fla. 86-28C ( $\mathrm{mm})$ and the MF Springcrest $(\mathrm{Mm})$. At the time of sample collection, these trees were yet to bear fruit and, therefore, their status as either MF or NMF was unknown. Leaves were freeze-dried and stored at either $-80 \mathrm{C}$ or room temperature.

Fruit were collected from the MF cultivars Flavorcrest and Fragar and from the NMF cultivar Carolyn at commercial harvest stage (about $6 \mathrm{~kg}$ for 'Flavorcrest' and 'Fragar' and $9 \mathrm{~kg}$ for 'Carolyn', measured by an Effegi penetrometer). They were ripened to the eating-ripe stage at 20C, then mesocarp was snapfrozen in liquid nitrogen and stored at $-80 \mathrm{C}$.

Southern analysis. DNA was prepared from freeze-dried leaves by the method of Jinghan (1992). About $2 \mu \mathrm{g}$ of DNA was digested with 20 units of EcoRI (New England Biolabs, Beverly, Mass.), electrophoresed on either $1 \%$ or $1.3 \%$ agarose gels in $1 \times \mathrm{TBE}$ overnight, and transferred to Hybond membrane (Amersham, Buckinghamshire) by the method of Southern (1975).

Membranes were hybridized overnight with 32-P randomly labelled insert DNA of peach ripening-related PG cDNAs, PRF3 or PRF1 (Lester et al., 1994), in $0.25 \%$ skim milk powder, $5 \times$ SSPE, and $0.01 \%$ SDS at $65 \mathrm{C}$. Filters were washed at low stringency in $2 \times \mathrm{SSC}, 1 \% \mathrm{SDS}$, or high stringency in $0.2 \times \mathrm{SSC}$, $0.5 \%$ SDS, and exposed to Kodak AR (Rochester, N.Y.) film with an intensifying screen at $-70 \mathrm{C}$ for 4 nights.

Phenotype scoring. Fruit were monitored on the tree during ripening. When they were judged to be eating ripe, they were assessed using sensory evaluation as either MF or NMF. This subjective method of assessment was used because it confirmed that the fruit were fully ripe and, also, because, even when fruit are fully ripe, variation in texture and firmness within the two fruit types can make penetrometer measurements unreliable for distinguishing between MF and NMF fruit. About six fruit were assessed from each tree.

Raising endoPG antisera to recombinant endoPG protein. Antiserum to peach endoPG was raised in rabbits using recombi- nant endoPG protein as antigen. The Escherichia coli vector pGEX was used to produce a recombinant fusion protein of endoPG fused to the carboxyl end of glutathione S-transferase (GST) of Schistosoma japonicum (Smith and Johnson, 1988) It was considered unnecessary to remove the GST portion before injection into rabbits; any anti-GST activity in the serum was not likely to interfere with the interpretation of western blotting results, since GST and endoPG proteins can be distinguished by their predicted molecular masses.

A BclI/BamHI fragment of the peach endoPG cDNA PFR5 coding for amino acids, 19-393 (Lester et al., 1994), of the enzyme was ligated into the BamHI site of pGEX3 (Amrad, Melbourne, Victoria). Insert DNA and flanking vector sequences were prepared by polymerase chain reaction (PCR) using primers M20 and M-20. The BamHI site at the 3' end of the fragment was created by including a BamHI recognition sequence at the $5^{\prime}$ end of the M20 primer. The $5^{\prime} \mathrm{BclI}$ site was internal toward the $5^{\prime}$ end of PRF5.

Ligations were performed using the Amersham Ligation system with $50 \mathrm{ng}$ of pGEX3 and $40 \mathrm{ng}$ of PRF5 BclI/BamHI fragment. High-efficiency HB101 E. coli cells (Promega, Madison, Wis.) were transformed with $20 \mathrm{ng}$ of plasmid DNA. Transformants containing the insert in the correct orientation were identified by DNA sequencing.

Recombinant protein GST-PG (molecular mass $67 \mathrm{kD}$ ) was prepared and purified by the method of Frangioni and Neel (1993).

Two New Zealand white rabbits were pre-bled and injected subcutaneously with $60 \mu \mathrm{g}$ of GST-PG attached to agarose beads. Booster injections of $50 \mu \mathrm{g}$ protein attached to beads were given at day 21 and 42. Serum samples were collected at day 98.

Preparation of cell wall extracts and western blotting. Cell wall extracts were prepared from fruit of the established MF cultivars Flavorcrest and Fragar and the NMF cultivar Carolyn. Northern analysis had been performed previously on the fruit of these

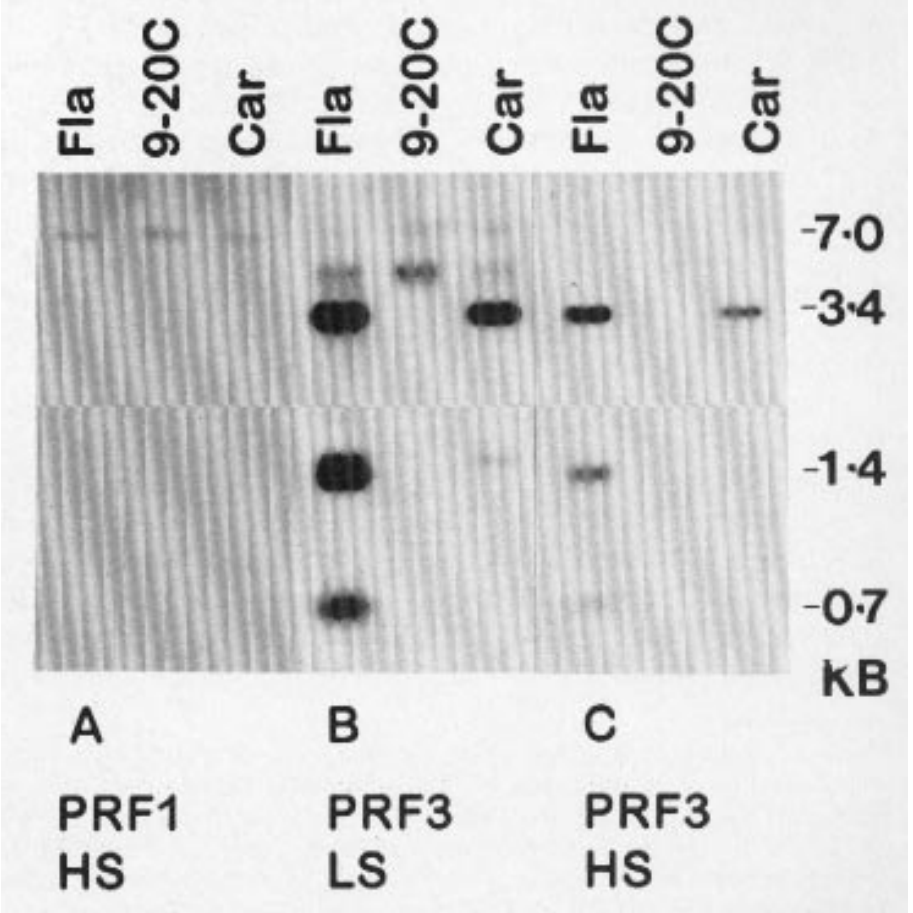

Fig. 1. Southern hybridization of EcoRI digested genomic DNA from melting flesh (MF) 'Flavorcrest' (Fla), nonmelting flesh (NMF) 'Fla. 9-20C' (9-20C) and NMF 'Carolyn' (Car) separated on a 1\% agarose gel and probed with (A) PRF1 washed at high stringency, (B) PRF3 washed at low stringency, or (C) PRF3 washed at high stringency. The size in kilobases of hybridizing bands is indicated on the right. 
cultivars (Lester et al., 1994).

Extracts were prepared by suspending $10 \mathrm{~g}$ of powdered frozen ripe peach fruit mesocarp (that had been in storage at -80C) in 20 $\mathrm{ml}$ of water. After centrifugation at $5000 \times \mathrm{g}$, the pellet was resuspended in $10 \mathrm{ml}$ of 0.1 m sodium citrate $(\mathrm{pH} 4)$ containing 20 $\mathrm{mm} \beta$-mercaptoethanol and $1.5 \mathrm{M} \mathrm{NaCl}$ and held at $4 \mathrm{C}$ overnight. After centrifugation at $5000 \times g$, the supernatant was spun in a microconcentrator (Centricon 30; Amicon, Beverly, Mass.) with a total of 2 volumes of $0.1 \mathrm{~m}$ sodium citrate $(\mathrm{pH} 4), 20 \mathrm{~mm} \beta$ mercaptoethanol, added at intervals to reduce the $\mathrm{NaCl}$ concentration. The final volume of cell wall extract solutions after centrifugation was about $500 \mu \mathrm{l}$. Samples of $20 \mu \mathrm{l}$, containing about $40 \mu \mathrm{g}$ of protein, were used for SDS-PAGE.

Samples of recombinant GST-PG protein $(5 \mu \mathrm{mg})$ attached to agarose beads were included on gels as a positive control in western blots. Proteins were separated on 10\% SDS-PAGE gels and transferred to nitrocellulose membrane by semi-dry western blotting (Kyhse-Anderson, 1984). Immunodetection was carried out using the Protoblot system of Promega according to the manufacturer's instructions.

\section{Results and Discussion}

Southern analysis of various MF and NMF peach cultivars with the peach fruit PG-related cDNA, PRF1 (Lester et al., 1994), revealed a single hybridizing EcoRI band of about $7 \mathrm{~kb}$ present in all cultivars. Results for the MF cultivar Flavorcrest and the NMF cultivars Fla. 9-20C and Carolyn are presented in Fig. 1A.

Southern analysis with the peach fruit PG-related cDNA, PRF3, detected a RFLP amongst MF and NMF cultivars. The MF cultivars Flavorcrest (Fig. 1 B and C) and Flordaking contained hybridizing EcoRI bands of 3.4, 1.4, and $0.7 \mathrm{~kb}$. The NMF cultivars Carolyn (Fig $1 \mathrm{~B}$ and C), Early Gold Queen, Fla. 86-28C, and Fla. 9-26C contained a single hybridizing EcoRI band of 3.4 kb. In the NMF cultivar Fla. 9-20C (Fig. 1C), Southern analysis with PRF3 detected no related sequences. A similar result for 'Fla. 9-20C' was obtained when a cDNA representing the complete open reading frame of PRF3 was used as a probe (results not shown). PRF3 has been identified as encoding the endoPG enzyme prevalent in ripe MF fruit (Lester et al., 1994).

A polymorphism in the endoPG gene between MF and NMF cultivars was consistent with the previous finding that the endoPGrelated RNA transcript in the NMF cultivar Carolyn was $250 \mathrm{bp}$ shorter than that of the MF cultivar Flavorcrest (Lester et al., 1994). Detecting an RFLP with the PRF3 cDNA confirmed it as a marker for mapping the endoPG gene with respect to the melting flesh locus. The complete absence of endoPG-related bands in the NMF cultivar Fla. 9-20C showed that a mutation in the form of a gene deletion was present in this cultivar. These preliminary findings supported the hypothesis that the NMF phenotype arises from a disturbance to normal endoPG gene expression. The random incidence of RFLPs between MF and NMF cultivars would be expected to be low, since isozyme studies indicate that genetic differences are minimal between commercial MF and NMF peach cultivars (Ibanez et al., 1993).

The difference in RFLP pattern between the NMF cultivars Fla. 9-20C and Carolyn suggested that a putative mutation in the endoPG gene was of more than one type. The mutation in 'Fla 920C' was in the form of a gene deletion, whereas, in 'Carolyn', endoPG-related sequences were present but in a different form to at least one of the alleles found in MF varieties. It cannot be excluded that the NMF trait arose from more than one source since it has existed for many hundreds of years. References to MF and NMF peaches can be traced to cultivars introduced to Northern America from Persia (Hedrick, 1917). The NMF trait is believed to have originated in varieties from China, the native home of the peach (Hedrick, 1917).

Several additional bands cross-hybridized with PRF3 at low stringency that were constant between MF and NMF cultivars (Fig. 1B), one of which corresponded to the 7-kb EcoRI band

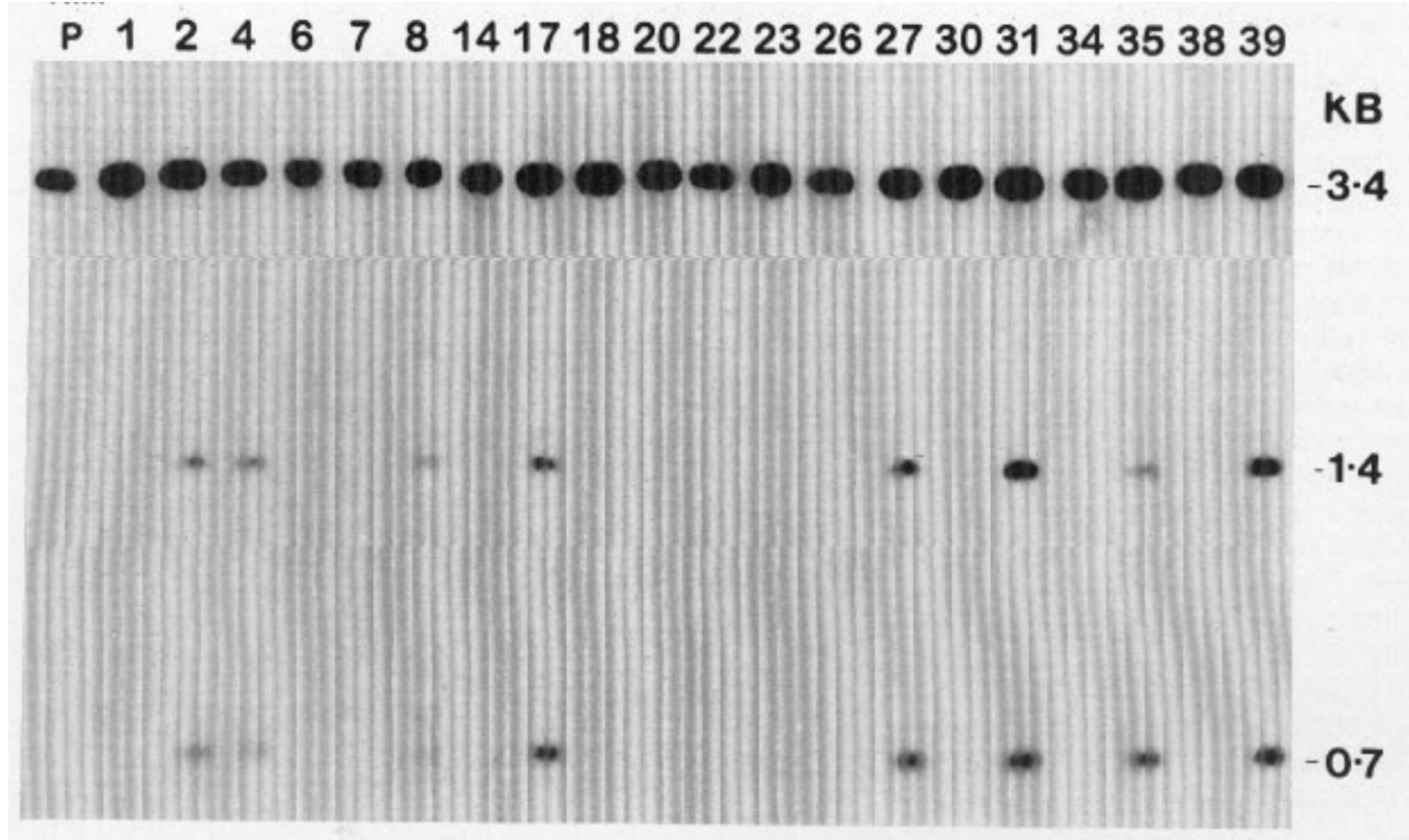

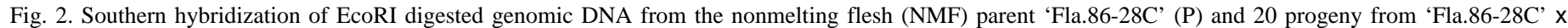

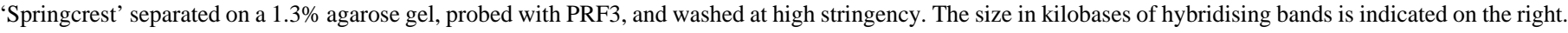


detected by PRF1. A third peach PG gene has been described and hybridization bands at $3.5 \mathrm{~kb}$ corresponded to those expected for this gene (Lee et al., 1990). There were bands in addition to these, and it was concluded that PG-related genetic sequences in peach made up a family of more than three genes.

Having demonstrated an RFLP in the endoPG gene between MF and NMF cultivars, the next step for mapping the gene to the melting flesh locus was to follow segregation of the RFLP in a population in which the melting flesh trait was segregating.

Classically, a morphological trait is mapped by RFLP analysis in an experimental population comprising polymorphic homozygous inbred parents, $\mathrm{F}_{1}$ individuals, and at least $50 \mathrm{~F}_{2}$ individuals (Gebhardt and Salamini, 1992). Such a population allows clear allelic analysis of a gene with respect to the RFLP and estimation of linkage between the RFLP marker and the trait. As an alternative to an $\mathrm{F}_{2}$ progeny, segregation may be followed in progeny of a backcross (Gebhardt and Salamini, 1992), in which case fewer individuals may be examined.

Homozygous inbred MF and NMF peach lines have not been developed. Using morphogenic polymorphic parents introduces genetic variability in the offspring, which may modify expression of a trait within the population. Even with morphogenic MF and NMF parents, the generation time of peach precluded raising a population specifically for this RFLP study. A backcross population of 20 trees produced from a MF x NMF cross, in which the MF trait was segregating 1:1, that was part of an established breeding program was used. Without the homozygous grandparents and only one parent available, this population did not permit allelic analysis of the gene. It was not anticipated that the genetic variability of the offspring would cause problems for scoring the fruit as either MF or NMF; however, the possibility could not be completely excluded.

Southern analysis of this population, from the cross 'Fla. 8628C' $x$ 'Springcrest', revealed the endoPG RFLP (using PRF3) detected previously between MF and NMF cultivars (Fig. 2). The 20 trees showed endoPG-related hybridizing bands in the two patterns of either three bands of 3.4, 1.4, and $0.7 \mathrm{~kb}$ (MF-like) or the 3.4-kb band alone (NMF-like).

The MF parent 'Springcrest' was not available for Southern analysis; the NMF parent 'Fla. 86-28C' displayed the expected NMF-like pattern (Fig. 2). The ratio in which the RFLP was present in the progeny was $8: 12$, which in 20 trees was acceptable as representing the expected Mendelian ratio $\left(\chi^{2}=0.45\right)$.

Since the 1.4- and 0.7-kb EcoRI endoPG-related bands were present in all MF $\left(M_{-}\right)$individuals, they could be said to represent the putative $M$ allele. The 3.4-kb EcoRI band only was present in NMF $(\mathrm{mm})$ cultivars except for 'Fla. 9-20C'. It could not be established that the $3.4-\mathrm{kb}$ band was allelic to the $1.4-$ and $0.7-\mathrm{kb}$ bands (and therefore the putative $m$ allele) from these experiments. However, it was concluded that the $1.45-\mathrm{kb}$ endoPG-related RNA detected in 'Carolyn' fruit (Lester et al., 1994) was a product of the gene represented by this band.

The intensity of hybridization of the $3.4-\mathrm{kb}$ band was consistently stronger than that of the 1.4 -and $0.7-\mathrm{kb}$ bands. Initially it was considered that the 1.4- and 0.7-kb bands represented a second related gene and the more intensely hybridizing $3.4-\mathrm{kb}$ band represented endoPG. This conclusion was ruled out by the fact that high-stringency washes did not distinguish between the two sets of bands. The stronger intensity of the $3.4-\mathrm{kb}$ band might be caused by repetitive sequences in the endoPG gene and, so, evidence of an aberration.

Considerable variation in fruit texture and firmness was present among the 20 trees of 'Fla.86-28C' $x$ 'Springcrest' progeny.
Nonetheless the fruit were judged to be MF or NMF according to methods usually used by the breeder working in the field (Table 1). The study was performed blind and there was no recourse for checking results. To confirm the phenotype results it would have been necessary to wait for the next fruiting season.

There was correlation in results on the melting flesh phenotype and the endoPG RFLP data for 17 out of the 20 trees (Table 1). If scoring the MF trait was not clear cut in every case as had been assumed initially, a result showing high but not absolute agreement might be obtained.

No clear definition exists for the classification of fruit as either $\mathrm{MF}$ or NMF, rather it relies on a form of assessment by the breeder that is subjective and depends on having had some experience with the trait. The trait must be scored within a few days when the fruit are fully ripe to overripe. This requires careful monitoring fruit on each tree at a time of year when the breeder is very busy. Considerable variation in texture and firmness may occur within the MF and NMF phenotypes, and the rate at which flesh softens also varies (Blake and Edgerton, 1946; W.B. Sherman, unpublished data).

To investigate further the hypothesis that the NMF phenotype arises from a mutation in the endoPG gene, we compared levels of the endoPG gene product in MF and NMF fruit using western blotting. Antiserum from recombinant GST-PG protein detected a 43,000-Mr protein band in the cell wall extract from ripe 'Flavorcrest' fruit. This band was assumed to represent the endoPG of peach fruit on the basis it was of the expected size and showed a ripening-related profile (Fig. 3B) that correlated with endoPG enzyme activity throughout ripening in 'Flavorcrest' fruit (Orr and Brady, 1993). Pre-immune serum did not detect the protein (Fig. 3A). EndoPG protein was detected in ripe fruit of MF 'Fragar' and it was not detected in ripe NMF 'Carolyn' (Fig. 3B). The apparent absence of endoPG protein in 'Carolyn' fruit correlated with the aberrant endoPG RNA transcript that was detected in this cultivar (Lester et al., 1994). It also correlated with the lack of significant levels of endoPG activity in NMF cultivars (Pressey and Avants, 1978).

Table 1. Restriction fragment length polymorphism, phenotype, and agreement between the two for progeny from 'Fla. $86-28 \mathrm{C}$ ' $x$ 'Springcrest'.

\begin{tabular}{lccc}
\hline \hline Tree & RFLP & Phenotype & Agreement \\
\hline 1 & NMF-like & NMF & + \\
2 & MF-like & NMF & - \\
4 & MF-like & MF & + \\
6 & NMF-like & NMF & + \\
7 & NMF-like & MF & - \\
8 & MF-like & MF & + \\
14 & NMF-like & NMF & + \\
17 & MF-like & MF & + \\
18 & NMF-like & NMF & + \\
20 & NMF-like & NMF & + \\
22 & NMF-like & NMF & + \\
23 & NMF-like & NMF & + \\
26 & NMF-like & NMF & + \\
27 & MF-like & MF & + \\
30 & NMF-like & NMF & + \\
31 & MF-like & MF & + \\
34 & NMF-like & NMF & + \\
35 & MF-like & MF & + \\
38 & NMF-like & MF & - \\
39 & MF-like & MF & + \\
\hline
\end{tabular}


Further work is required to confirm the endoPG gene as the melting flesh locus. It would be preferable to map endoPG with respect to the $\mathrm{MF}$ trait in a $\mathrm{F}_{2}$ population containing MF homozygotes and heterozygotes. Although the trait is reported as completely dominant (Bailey and French, 1949), the occurrence of an intermediate phenotype, especially in a genetically variable population, cannot be excluded. Such a phenotype would mean that a backcross population would not be reliable for mapping the trait. By examining a large population of trees, it could be established whether the statistically significant linkage between RFLP and phenotype exists. We have developed a PCR assay that could be used for this purpose (data not shown). The extent to which expression of the MF trait is affected by genetic variability could be considered further. For this purpose, it would be useful to study the relationship between levels of endoPG protein in fruit and their firmness in a genetically variable population.

A genetic marker for the MF trait is especially desirable since the trait is expressed when trees are mature and in a transient fashion. Traditionally, NMF peaches have been bred for canning purposes and MF peaches for fresh-market fruit. A NMF peach attractive for fresh eating is considered to have considerable commercial advantage in terms of storability, and breeding programs aimed at producing one are underway (Sherman et al., 1990). A genetic marker for the MF trait is likely to accelerate these programs.

This RFLP study is presented in context with biochemical evidence supporting a possible role for endoPG in the MF trait and consideration of the practical aspects of scoring the trait in the field. Our additional findings of a deletion of the endoPG gene in NMF 'Fla. 9-20C' and lack of enzyme protein in NMF 'Carolyn' provide further correlation between absence of endoPG activity and the NMF phenotype.

\section{Literature Cited}

Arumuganathan, K. and E. Earle. 1991. Nuclear DNA content of some important plant species. Plant Mol. Biol. Rpt. 9:208-218

Bailey, J.S. and H.P. French. 1949. The inheritance of certain fruit and foliage characters in peach. Mass. Agr. Expt. Sta. Bul. 452:2-31

Belthoff, L.E., R. Ballard, A. Abbott, W.V. Baird, P. Morgens, A. Callahan, R. Scorza, and R. Monet. 1993. Development of a saturated linkage map of Prunus persica using molecular based marker systems. Acta Hort. 336:51-56

Blake, M.A. and L.J. Edgerton. 1946. Standards for classifying peach characters. New Jersey Agr. Expt. Sta. Bul. 728

Chaparro, J.X., D.J. Werner, D. O’Malley, and R.R. Sederoff. 1994. Targetted mapping and linkage analysis of morphological isozyme and RAPD markers in peach. Theor. Appl. Genet. 819:1-11

Fischer, R.L. and A.B. Bennett. 1991. Role of cell wall hydrolases in fruit ripening. Annu. Rev. Plant Physiol. Plant Mol. Biol. 42:675-703

Fishman, M.L., B. Levaj, D. Gillespie, and R. Scorza. 1993. Changes in the physicochemical properties of peach fruit pectin during on-tree ripening and storage. J. Amer. Soc. Hort. Sci. 118:343-349

Frangioni, J.V. and B.G. Neel. 1993. Solubilization and purification of enzymatically active glutathione S-transferase (pGEX) fusion proteins. Anal. Biochem. 210:179-187

Gebhardt, C. and F. Salamini. 1992. Restriction fragment length polymorphism analysis of plant genomes and its application to plant breeding. Intl. Rev. Cytol. 135:201-237

Giovannoni, J.J., D. DellaPenna, A.B. Bennett, and R.L. Fischer. 1990. Polygalacturonase and tomato fruit ripening. Annu. Rev. Hort. Sci. 108:405-409

Hedrick, U.P. 1917. The peaches of New York. Rpt. NY Agr. Expt. Sta., 1916

Hesse, C.O. 1975. Peaches, p. 285-335. In J. Janick and J.N. Moore (eds.). Advances in fruit breeding. Purdue Univ. Press, West Lafayette, Ind.

Ibanez, M.A., M.A. Di Renzo, and M.M. Poverene. 1993. Isozyme diversity among and within peach groups: Freestone, clingstone and nectarines. Sci. Hort. 53:281-288

Jhingan, A.K. 1992. Efficient procedure for DNA extraction from lyophilized plant material. Methods Mol. Cell Biol. 3:185-187

Kyhse-Anderson, J. 1984. Electroblotting of multiple gels: A simple apparatus without buffer tank for rapid transfer of protein from polyacrylamide to nitrocellulose. Biochem. Biophys Methods 10:203-209

Lee, E., J. Speirs, J. Gray, and C.J. Brady. 1990. Homologies to the tomato endoPG in the peach genome. Plant Cell Environ. 13:513-521

Lester, D.R., J. Speirs, G. Orr, and C.J. Brady. 1994. Peach (Prunus persica) endoPG cDNA isolation and mRNA analysis in melting and non-melting peach cultivars. Plant Physiol. 105:225-231

Monet, R. 1989. Peach genetics: Past, present and future. Acta Hort. 254:49-57

Orr, G. and C. Brady. 1993. How endoPG activity relates to fruit softening in a dessert peach. Postharvest Biol. Technol. 3:121-130

Postlmayr, H.L., B.S. Luh, and S.J. Leonard. 1956. Characterization of pectic changes in freestone and clingstone peaches during ripening and processing. Food Technol. 10:618

Pressey, R. and J.K. Avants. 1973. Separation and characterization of endoPG and exopolygalacturonase from peaches. Plant Physiol. 52:252-256

Pressey, R. and J.K. Avants. 1978. Differences in polygalacturonase composition of clingstone and freestone peaches. J. Food Sci. 43:1415-1423

Sherman, W.B., B.L. Topp, and P.M. Lyrene. 1990. Non-melting flesh for fresh market peaches. Proc. Fla. State Hort. Soc. 103:293-294

Shewfelt, A.L. 1965. Changes and variations in the pectic constituents of ripening peaches as related to product firmness. J. Food Sci. 30:573-576

Smith, D.B. and K.S. Johnson. 1988. One-step purification of polypeptides expressed in Escherichia coli as fusions with glutathione S-transferase. Gene 67:31-40

Southern, E.M. 1975. Detection of specific sequences among DNA fragments separated by gel electrophoresis. J. Mol. Biol. 98:503-517 